\title{
Estimation of Corn Leaf Area Index and Ground Cover With Vegetation Indices as a Result of Irrigation Dose
}

\author{
C. D. Papanikolaou ${ }^{1} \&$ M. A. Sakellariou-Makrantonaki ${ }^{1}$ \\ ${ }^{1}$ Department of Agriculture, Crop Science and Rural Environment, Laboratory of Agricultural Hydraulics, \\ University of Thessaly, Volos, Greece \\ Correspondence: C. D. Papanikolaou, Department of Agriculture, Crop Science and Rural Environment, Fytokou \\ Street, 38446, Volos, Greece. E-mail: hpapan@uth.gr
}

Received: September 7, 2020

Accepted: October 29, $2020 \quad$ Online Published: November 15, 2020

doi:10.5539/jas.v12n12p234

URL: https://doi.org/10.5539/jas.v12n12p234

The research is financed by the «Stavros Niarchos Foundation» in the frame of the invitation "SCHOLARISHIP GRANTING FOR POST-DOCTORATE RESEARCH" of the University of Thessaly, which is implemented by the University of Thessaly.

\begin{abstract}
New technologies have been implemented in the agricultural sector to improve crop production and resource management including irrigation water. A three-year long project was conducted to determine whether vegetation indices (VIs) could be used to estimate the leaf area index (LAI) as well as the soil cover fraction $\left(\mathrm{f}_{\mathrm{c}}\right.$ ) at different crop growth stages in order to use these parameters in a future study concerning irrigation through drones. A low cost unmanned aerial vehicle (drone) and a multispectral camera were used to calculate different VIs of corn (Zea mays). The irrigation scheduling based on the FAO Penman-Monteith equation and the drip irrigation method were used. Three treatments were organized in three replications and the irrigation doses were equal to $100 \%, 75 \%$, and $50 \%$ of the daily evapotranspiration respectively. The Simple and Multiple Regression analysis were used and different equations were formed where the VIs were the predictor variables and the LAI and $\mathrm{f}_{\mathrm{c}}$ the predicted ones. According to the two-year period data (2018-2019), during 2018 the average maximum LAI in the full irrigation treatment $(100 \%)$ was 4.1 . In the medium irrigation treatment (75\%) the LAI was 4.0. The LAI in the third treatment (50\%) was 3.9. In 2019, the LAI was 3.7 (100\% treatment). In the second treatment, the LAI was 3.3. The LAI in the third treatment was 3.0. According to the results different VIs and prediction equations could be used to estimate the LAI values with high accuracy with the in situ measurements as well as the soil cover fraction.
\end{abstract}

\section{Introduction}

The agricultural sector is of high economic importance worldwide especially because of the recent economic crisis, as well as the crisis following the Covid-19 pandemic. This sector is of equal, if not greater importance for Greece, too. One of the problems of the agricultural sector both worldwide and in Greece is the rational management of natural resources and especially of irrigation water. The largest amount of water is consumed for the agricultural production (Goupta, Sarangi, Singh, Parihar, \& Varghese, 2016). In highly irrigated crops, irrational irrigation planning is applied (USDA, 2004). This problem has even greater dimensions if we take into consideration the need for a sustainable management of these resources so that they remain available in the same quantities for the future generations as well (Chartzoulakis \& Bertaki, 2015). In addition, until a few months ago, water users outside of agriculture, had specific water needs that are now changing dramatically due to the Covid-19 pandemic. Especially in Greece, the needs for water were already on the rise, mainly due to the increased demand during the summer months as a result of the high influx of tourists. These needs will now further increase as a result of hygiene requirements to deal with emergency situations such as the recent pandemic.

The application of new technological advances in everyday agricultural practice is constantly gaining new supporters (Maas, 2008). Unmanned aerial vehicles (drones) are used in conjunction with multispectral cameras to calculate vegetation indices and estimate the plant physiological status. This combination is one of the new technologies currently being implemented in agricultural production (Sylvester, 2018). Particularly the use of drones in agricultural production is a new challenge for the Greek agricultural practice. The multispectral indices, 
among other uses, are used to estimate plant characteristics such as the plant growth rate. A number of different vegetation indices are used to estimate the plant growth. Some of them estimate the absolute growth rate, the total dry biomass production (Watson, 1956) and the leaf area index (Williams, 1946). Especially the leaf area index is an important parameter that affects the photosynthesis of plants and is used in models predicting the rate of photosynthesis (Boedhram, Arkebauer, \& William, 2001). The leaf area index gives information about the normal growth of plants and the final production that the plant is expected to achieve (Towers, Strever, \& Poblete-Echeverría, 2019). The leaf area index (LAI) denotes the area covered by the cultivation foliage per unit area of soil (Towers et al., 2019). The LAI is used as an independent variable in agricultural management among other parameters.

The multispectral indices could be used in irrigation scheduling (Mulla, 2013; Papanikolaou \& Sakellariou-Makrantonaki, 2019, 2020). According to Food and Agriculture Organization (1998) in irrigation scheduling it is necessary to calculate the crop evapotranspiration (ETc). The ETc is the product of the multiplication of the reference evapotranspiration (ETo) of an area with the crop coefficient (Kc) for each stage of crop development. A great number of direct and indirect methods are used to calculate the ETo and different crop coefficients are calculated for each one of them as well as for each plant species and each growth stage of plants (FAO, 1998). Consequently, when the multispectral indices are used to estimate the ETo, it is necessary that new crop coefficients be calculated that are suitable for use with this new method of ETo estimation. However, the crop coefficients depend on the growth of the cultivated crop (Savva, Frenken, Mudima, Chitima, \& Tirivamwe, 2002) and therefore are related directly to LAI of the crop (Shahrokhnia \& Sepaskhah, 2013). Also, the crop coefficients are affected by the soil cover fraction $\left(f_{c}\right)$ that the leaf surface of the cultivated plant produces too (Gao et al., 2009).

A number of different vegetation indices have already been proposed to estimate various plant characteristics. Toureiro, Serralheiro, Shahidian, and Sousa (2017), proposed the Normalized Difference Vegetation Index (NDVI) to estimate the leaf area index. Toureiro et al. (2017) proposed the same vegetation index to estimate the $f_{c}$ of the crop foliage to the soil surface. However, Gitelson et al. (2003) claim that the NDVI index has the disadvantage of over or underestimating the LAI when its values are high. To overcome this disadvantage, other vegetation indices were developed such as the Wide Dynamic Range Vegetation Index (WDRVI), the Second Modified Soil Adjusted Vegetation Index $\left(\mathrm{MSAVI}_{2}\right.$ ) and the Perpendicular Vegetation Index (PVI) which also have the advantage that they are not affected by the soil characteristics as well as the Ratio Vegetation Index (RVI) which is very sensitive to LAI changes (Towers et al., 2019). A common characteristic of the above indices is the fact that they use the red and near-infrared (NIR) band of the spectrum (Towers et al., 2019). In general, studies have shown that the choice of the appropriate band of the spectrum is crucial to the calculation of the vegetation indices and affects their effectiveness in the LAI estimations (Ryu, Suguri, \& Umeda, 2009) while the appropriate combination of different bands results in even greater sensitivity of those indices to LAI estimation and makes them suitable for use in different conditions (such as different environments, cultivation practices, plant growth stages) (Nakanishi et al., 2012). Other researchers suggest vegetation indices to estimate LAI that use the green band of the spectrum such as the Green Normalized Difference Vegetation Index (GNDVI) (Din, Zheng, Rashid, Wang, \& Shi, 2017) and the Red Edge Chlorophyll Index ( $\mathrm{CI}_{\text {red-edge }}$ ) (Towers et al., 2019). In many studies different vegetation indices have been used to estimate the crop production, as a function of the soil cover fraction of the plant leaves (Potgieter et al., 2017).

The present study focuses on the corn crop. Corn covers a large agricultural area in Greece as it is well adapted to the climatic conditions of the country. On the other hand it is an important crop for the Greek economy, mainly for the high nutritional value of the seeds for both humans and animals. Furthermore, it is one of the cultivated plant species that can be used either for biomass production or bioethanol (Ambrosio et al., 2017). Finally, it is a plant that is affected by the different irrigation doses (Toureiro et al., 2017).

This study is part of a three-year project. The objective of the current research was to study if it is feasible to use a drone and a multispectral camera to calculate vegetation indices in corn, in the Greek climatic conditions, and to use them to estimate the leaf area index and the soil cover fraction of the corn leaf area. It is the first time that such a study is organized and implemented in the climatic conditions of Central Greece. The main hypothesis was that if specific vegetation indices can be used to estimate the corn LAI and the soil fraction cover in the climatic conditions of Central Greece.

According to the above mentioned there are theoretical and practical implications. It is the first time that a low cost multispectral camera and a drone are used in the Greek climatic conditions to estimate the LAI of corn and the soil ground cover. The know-how is going to be used as the basis for other research projects in the future as well as in theoretical training of farmers, under graduate and post graduate students. In practice, the know-how is 
going to be used in every day crop production procedure in the frame of an optimal management of the natural resources such as irrigation water.

\section{Materials and Methods}

\subsection{Experimental Site Description}

A three-year long research project was designed and implemented at the Experimental Farm of the Department of Agriculture, Crop Production and Rural Environment, of the University of Thessaly, in the Velestino area, Magnesia, Central Greece (latitude: $39^{\circ} 02^{\prime}$ North, longitude: $22^{\circ} 45^{\prime}$ East). The altitude of the farm is about 70 meters above sea level. According to a previous soil study, the soil of the experimental field is characterized as a well-drained soil belonging to the Typic Xerorthent subgroup. Throughout the field, the granulometric composition of the soil is classified between medium to moderately coarse-grained or moderately fine-grained, with clay and clay-loam textures. The soil $\mathrm{pH}$ was measured and found to be between 7.9 to 8.1 which is favourable for most open field crops. The average Cation Exchange Capacity at the depths of $0-30 \mathrm{~cm}$ and $30-60 \mathrm{~cm}$ was 32.30 me per $100 \mathrm{~g}$ of soil. In general, the level of nutrient availability is satisfactory so that high yields can be achieved even with no fertilization. The soil texture is $38 \%$ clay, $32 \%$ silt, and $30 \%$ sand and classified as clay to clay loam according to the USDA classification. The soil moisture at field capacity and at the permanent wilting point of the specific soil was determined by means of gradual removal of water in undisturbed soil samples. The pressure plate device was used. The soil samples were taken from two different depths, $0-30 \mathrm{~cm}$ and $30-60 \mathrm{~cm}$. The average soil moisture at field capacity and at the permanent wilting point at the depth of $0-60 \mathrm{~cm}$ was 0.387 and $0.218 \mathrm{~cm}^{3} \mathrm{~cm}^{-3}$, respectively. The Field Capacity and the Permanent Wilting Point were used to calculate the Total Available soil Water (TAW) and the Readily Available soil Water (RAW) (FAO, 1998). The Practical Applied irrigation dose was calculated from the RAW value for $0.60 \mathrm{~m}$ effective root depth and depletion fraction 0.50 . The Practical Applied irrigation dose was found equal to $51 \mathrm{~mm}$ and it was used to calculate the maximum irrigation interval for the most crucial month of the irrigation period. The maximum irrigation interval, eight days, was calculated as the quotient of the division between the Practical Applied irrigation dose and the average reference evapotranspiration of the crucial month for the Central Greek conditions (July, ETo $\approx 6.3 \mathrm{~mm} / \mathrm{d}$ ), based on recorded data.

\subsection{Experimental Design}

Three irrigation treatments in three replications were organized and the randomized complete block design was used (Mongomery \& Runger, 2003; Papanikolaou \& Sakellariou-Makrantonaki, 2012, 2019; Papanikolaou, Giouvanis, Karatasiou, Dimakas, \& Sakellariou-Makrantonaki, 2018; Sakellariou-Makrantonaki \& Papanikolaou, 2008a, 2008b, Sakellariou-Makrantonaki, Papanikolaou, \& Mygdakos, 2009). The treatments were: a) surface drip irrigation that covered the full water needs of the corn (I-100), b) surface drip irrigation that covered the $75 \%$ of the water needs of corn (I-75) and c) surface drip irrigation that covered the $50 \%$ of the water needs of the corn (I-50). The irrigation dose was calculated according to the daily evapotranspiration (ETd) following the procedure that FAO (1998) have already proposed.

\subsection{Agronomic Management}

The corn was sown on 04/17/2018 and 04/22/2019 and a four-row seeder was used. Each of the four rows consisted of 96 plants so as to maintain a distance of $13 \mathrm{~cm}$ between the plants, while the distance between the rows was 80 $\mathrm{cm}$. The total surface area of each plot was $30 \mathrm{~m}^{2}$. So, the equivalent total number of plants per Ha was 9,600. The harvest took place in the second 10-days of September (728 Growing Degree Days) in both years. The treatments were free of nitrogen fertilization. The weeds were controlled through two chemical applications and one hand carving. The first chemical weeds control was applied before the plant emergence and the second one after the emergence (Papanikolaou \& Sakellariou-Makrantonaki, 2019). The hand carving was conducted when the corn was $40 \mathrm{~cm}$ high and before the installation of the drip irrigation laterals.

The irrigation doses were applied through a drip irrigation system. First and second class delivery laterals made of polyvinyl chloride (PVC) were used. The distance between the drip irrigation laterals was $1.60 \mathrm{~m}$. The distance between the emitters was $0.50 \mathrm{~m}$ and its average flow rate was $4 \mathrm{~L} / \mathrm{h}$. The drip irrigation program started on $05 / 16 / 2018$ and $05 / 31 / 2019$. Until then, the first cultivation period, 2018, two sprinkler irrigations had been applied in order for optimum crop emergence to be achieved while the next year three sprinkler irrigations were applied. Flowmeters were placed at each plot and the exact amount of irrigation water was recorded after every irrigation. The irrigation dose was applied every six days, two days earlier than the maximum irrigation interval which was calculated according to the field properties mentioned above (Papanikolaou \& Sakellariou-Makrantonaki, 2019). 


\subsection{Data Collection}

\subsubsection{Measurement of LAI and Soil Cover Fraction}

Weekly measurements of LAI and soil cover fraction were taken starting at the $6^{\text {th }}$ week after sowing in 2018 and 2019. The measurements were taken from the two middle rows of each plot. Every plant in an area of $2 \mathrm{~m}^{2}$ was measured. The SunScan SS1 sensor was used to measure the LAI. Four measurements were taken from both of the two sites of the two middle rows of the plot and their average value was recorded.

The real soil cover fraction of the leaf area was measured from the same multispectral photos which were used to calculate the VIs. The measurements covered a specific area of each plot including the four rows and the space between them. The ImageJ software was used to measure the shadow of the plant leaves on the soil. The percentage of the leaf soil cover fraction was the quotient between the shadow area of the leaves and the real area of the shadowed soil.

\subsubsection{Metoeorological Data}

The daily meteorological data as well as the daily ETo were recorded by an agrometeorological station, located $50 \mathrm{~m}$ from the treatments (average distance). The climate of the area is a typical Mediterranean one as the summers are hot and the winder is cool and humid. The mean daily air temperature and the total rainfall (10-day average values) in the farm area, during the 2018 and 2019 cultivating period, are shown in the Figures 1a and 1b, schematically and are compared to the corresponding average values of the last 25 years. This figure shows that in both years (2018-2019) the mean air temperature did not fluctuate much from the values of an average year. However, during the period from May to August 2018, the mean temperature was lower than the average values of the last 25 years. The difference was $2{ }^{\circ} \mathrm{C}$ to $3{ }^{\circ} \mathrm{C}$ while the maximum value, $6{ }^{\circ} \mathrm{C}$, was recorded during the last ten-days of June. On the other hand, during the 2019 period, the air temperature was much closer to the temperature of the average year, with an exception between 10 and 20 July, when the temperature dropped as a result of rainfall.

According to the collected data and the Figure below, during the cultivating period of 2018, the rainfall was high. The total actual rainfall from the sowing to the end of August was $242.0 \mathrm{~mm}$. About half of this rainfall $(118.0 \mathrm{~mm})$ fell during a thirty-day period of time beginning from 10 of June to 10 of July. Those thirty days the rainfall alone covered the corn water needs which were high as a result of the high growth rate of the crop. In a normal year, about five more irrigations would have been applied taking into consideration the recorded data for the area in the past. In the year 2019, the total actual rainfall between the sowing date and the end of August was just $41.0 \mathrm{~mm}$. During the irrigation period, the rainfall was only $23 \mathrm{~mm}$ and the crop water needs were mainly covered by the irrigations. 


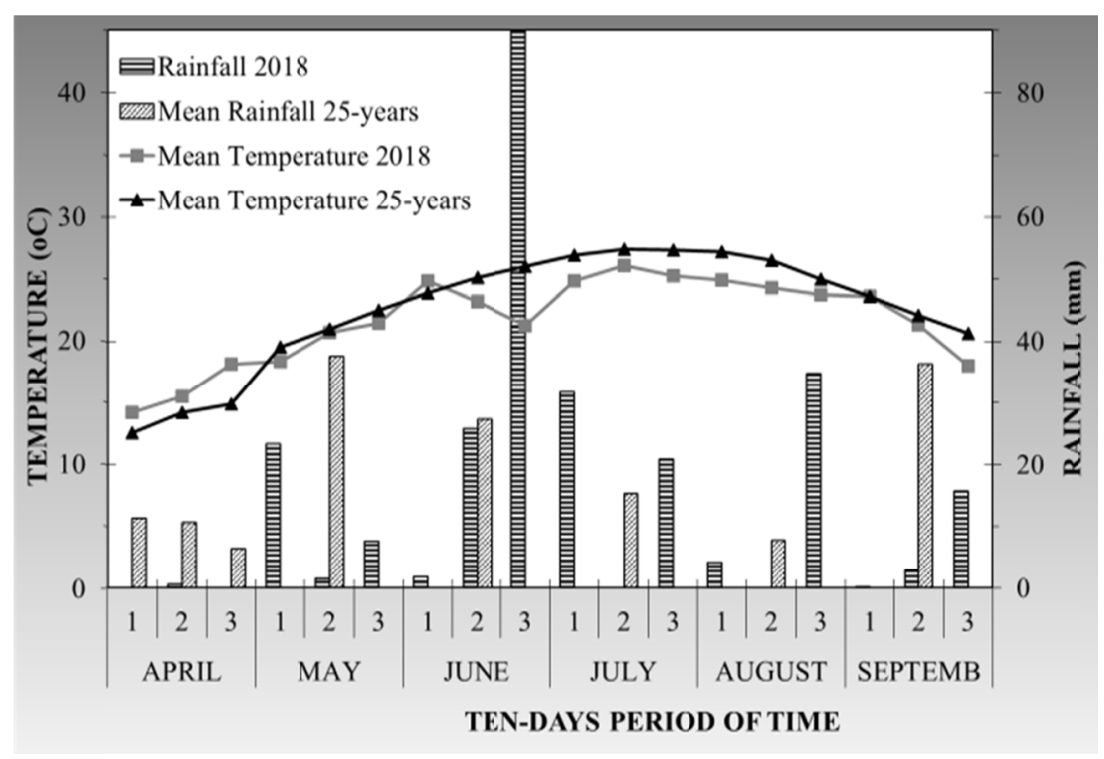

(a)

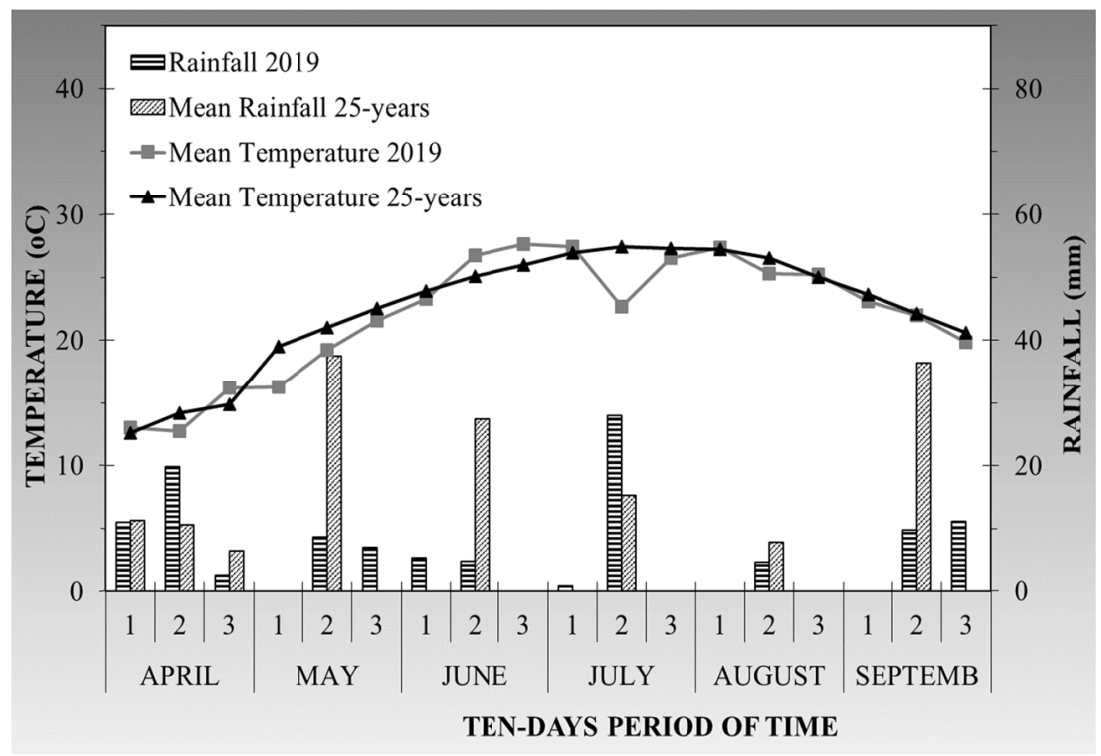

(b)

Figure 1. Average daily temperature and total rainfall of the year 2018 (a) and 2019 (b) in comparison with the average values of the last 20 years

\subsubsection{Estimation of Vegetation Indices}

In the present study the NDVI, WDRVI, RVI, GNDVI indices were used. Additionally, the Green Chlorophyll Index (CIg) was also used instead of the Red Edge Chlorophyll Index. The NDVI (Normalized Difference Vegetation Index) was calculated with the following equation (Xue \& Su, 2017):

$$
N D V I=\frac{N I R-R E D}{N I R+R E D}
$$

Where,

NIR: is the near-infrared channel of the multispectral camera centered at $660 \mathrm{~nm}$ with an interval -10 to $+10 \mathrm{~nm}$; RED: is the red channel of the multi-spectral camera centered at $850 \mathrm{~nm}$ with an interval -20 to $+20 \mathrm{~nm}$. 
The WDRVI (Wide Dynamic Range Vegetation Index) can be used with values of LAI higher than 2 while the NDVI is used when the LAI is lower than 1 (Gitelson, 2004). This index was calculated with the following equation (Gitelson, 2004):

$$
W D R V I=\frac{a \times N I R-R E D}{a \times N I R+R E D}
$$

Where,

a: is a coefficient value of 0.20 .

The RVI (Ratio Vegetation Index) was used to estimate the LAI, the dry biomass of the plant leaves, and the leaf chlorophyll content (Ghosh, Samui, \& Narayanan, 2003). This index was calculated with the following equation:

$$
R V I=\frac{N I R}{R E D}
$$

The GNDVI (Green Normalized Difference Vegetation Index) was used to estimate the LAI and biomass (Hunt, Hively, Daugtry, \& McCarty, 2008). This index was calculated with the following equation:

$$
G N D V I=\frac{N I R-G R E E N}{N I R+G R E E N}
$$

Where,

GREEN: is the green channel of the multispectral camera centered at $550 \mathrm{~nm}$ with an interval -10 to $+10 \mathrm{~nm}$.

The CIg (Green Chlorophyll Index) was used to estimate the leaf chlorophyll content (Lin et al., 2019). Because the leaf chlorophyll content is directly correlated with the plant leaf area, this VI was used to estimate the LAI too. This index was calculated with the following equation:

$$
C I_{g}=\frac{N I R}{G R E E N}-1
$$

A multi-spectral camera was used to take photos of the experimental field during the cultivation period. These photos were used to calculate the above vegetation indices. This multi-spectral camera uses three different channels, the red (RED $660 \mathrm{~nm}$ ), the green (GREEN, $550 \mathrm{~nm}$ ), and the near-infrared (NIR, $850 \mathrm{~nm}$ ). It could be remotely controlled via WiFi by a simple smartphone where the appropriate software had been installed. The photos were geo-referenced as a GPS was connected to the camera. Additionally, free software was used in photo calibration while another one, the QGIS ver. 2.18, was used to calculate the vegetation indices (Papanikolaou \& Sakellariou-Makrantonaki, 2019).

Both the multispectral camera and the GPS were hooked under an unmanned aerial vehicle (drone). The full equipment (drone and camera) was used to take photos from a specific height of about $4.0 \mathrm{~m}$ above each plot at midday (between 12:30 and 14:30 when the sun reaches its zenith) (Foster, Kakani, \& Mosali, 2017; Papanikolaou \& Sakellariou-Makrantonaki, 2019).

\subsection{Statistical Analysis}

The Minitab ver. 16 for Windows Statistical Package was used to analyze the data. The one-way analysis of variance (ANOVA) and the Simple and Multiple Linear Regression analysis tools were applied at a significance level of $\mathrm{P}<0.05$. The regression analysis was used to calculate equations to predict the LAI and the soil cover fraction. Several different vegetation indices were the independent variables while the dependent variables were the LAI and the $\mathrm{f}_{\mathrm{c}}$.

\section{Results and Discussion}

\subsection{Estimation of LAI With VIS}

Different irrigation doses affect the plant growth and LAI as well. 


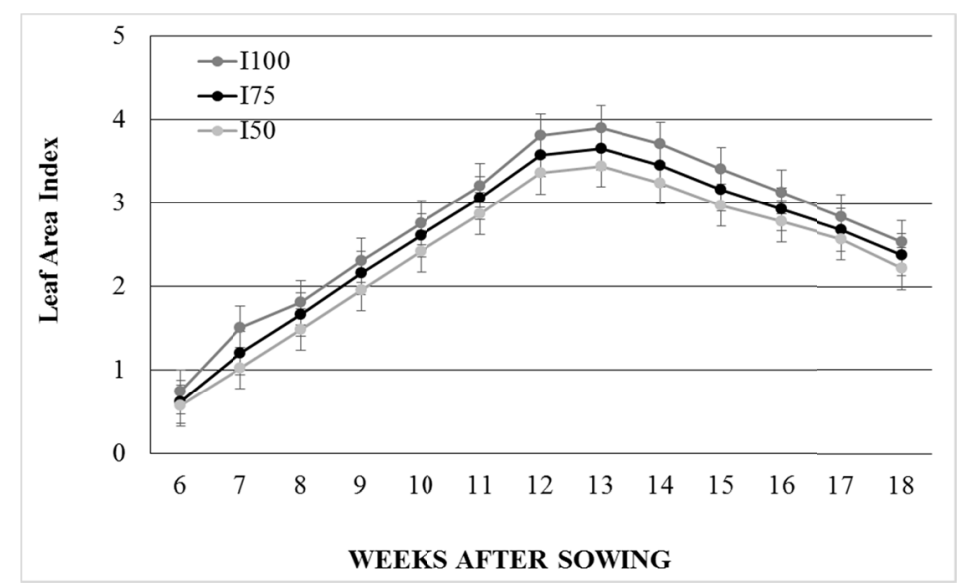

Figure 2. The progress of the average LAI values of corn in the three treatments during the growing period

The average LAI values during the growing season of corn are shown in Figure 2. The full irrigation treatment gave higher LAI values as the plants were higher and more robust than the plants in the other two treatments in both years. The maximum average LAI value (for the two years 2018 and 2019) in the I-100 treatment was 3.9 statistically higher than the 3.5 and 3.2 LAI values in the I-75 and I-50 treatments respectively.

Table 1. Equations which were produced to estimate the LAI of corn using different VI and the corresponding $\mathrm{R}^{2}$

\begin{tabular}{lll}
\hline Equation (Eq.) & $\mathbf{R}^{2}$ & Eq. No \\
\hline$L A I_{I-100}=7.43 \times N D V I_{I-100}-1.28$ & 0.92 & $(6)$ \\
$L A I_{I-75}=7.41 \times N D V I_{I-75}-1.39$ & 0.84 & $(7)$ \\
$L A I_{I-50}=7.45 \times N D V I_{I-50}-1.42$ & 0.77 & $(8)$ \\
$L A I_{I-100}=3.77 \times W D R V I_{I-100}+3.17$ & 0.93 & $(9)$ \\
$L A I_{I-75}=4.53 \times W D R V I_{I-75}+3.23$ & 0.86 & $(10)$ \\
$L A I_{I-50}=5.07 \times W D R V I_{I-50}+3.66$ & 0.66 & $(11)$ \\
$L A I_{I-100}=0.48 \times R V I_{I-100}+0.12$ & 0.84 & $(12)$ \\
$L A I_{I-75}=0.50 \times R V I_{I-75}+0.17$ & 0.77 & $(13)$ \\
$L A I_{I-50}=0.56 \times R V I_{I-50}+0.09$ & 0.73 & $(14)$ \\
$L A I_{I-100}=12.00 \times G N D V I_{I-100}-5.77$ & 0.98 & $(15)$ \\
$L A I_{I-75}=10.80 \times G N D V I_{I-75}-4.75$ & 0.99 & $(16)$ \\
$L A I_{I-50}=12.10 \times G N D V I_{I-50}-5.15$ & 0.98 & $(17)$ \\
$L A I_{I-100}=0.62 \times C I g_{I-100}+0.94$ & 0.79 & $(18)$ \\
$L A I_{I-75}=0.61 \times C I g_{I-75}+0.81$ & 0.72 & $(19)$ \\
$L A I_{I-50}=0.59 \times C I g_{I-50}+0.78$ & 0.65 & $(20)$ \\
\hline
\end{tabular}

According to Table 1, 15 different equations were formed to estimate the LAI for each treatment. In each of these equations, only one VI was used to predict the LAI values either in the I-100 treatment or the I-75 and I-50 ones. The correlation coefficient $\left(\mathrm{R}^{2}\right)$ ranged from 0.65 to 0.99 according to the VI that was used. As was expected the GNDVI was the VI that predicts the LAI with very high accuracy for the three treatments as the $\mathrm{R}^{2}$ reached values from 0.98 to 0.99 . Many kinds of research have shown similar results as the NIR and GREEN bands which are used in GNDVI are more sensitive to leaf area changes than the red one which is used in NDVI, RVI, and WDRVI. Alternatively, the NDVI can be used to predict the LAI of corn during the growing period with high accuracy too for the I-100 treatment while in the treatments I-75 and I-50 the accuracy is lower but acceptable $\left(\mathrm{R}^{2}=0.77-0.84\right)$. The CIg index gave the weakest predictions of LAI for all of the three treatments as expected. Many kinds of 
research have shown that the $\mathrm{CIg}_{\text {(RED-EDGE) }}$ is a VI more sensitive than the CIg one. However, it was not feasible to use it because of limitations in the multispectral camera standards.

The LAI values in the I-75 and I-50 treatments were not different statistically. The main objective of this study was to examine whether a drone and a multispectral camera can be used to estimate the LAI of corn plants using vegetation indices such as the NDVI, the WDRVI, the RVI, the GNDVI and the CIg in the climatic conditions of Central Greece. In other words, the purpose was to extract a mathematical equation in which the dependent variable would be the average value of the LAI per week of the growing season and the independent variables were one or more of the above indices. The Simple and the Multiple Regression method were used to analyze the data and to form the equations.

\subsection{Estimation of Soil Cover Fraction With VIS}

The soil cover fraction $\left(f_{c}\right)$ is closely related to the plant growth and is affected by the irrigation dose, as does the plant growth. The full irrigation treatment gave higher plants and higher LAI values (mean values of the two years 2018-2019) so the $f_{c}$ values were higher than the deficit irrigation treatments (mean values of the two years 2018-2019). The mean difference of the $f_{c}$ between the pairs of treatments I-100 and I-75, I-100 and I-50, and I-75 and I-50 were $0.065,0.134$, and 0.069 respectively. In percentages, the $\mathrm{f}_{\mathrm{c}}$ in the full irrigation treatment was $6.7 \%$ higher than in the I-75 treatment and $13.9 \%$ higher than in the I-50 treatment. Similarly, the percentage between the I-75 and the I-50 treatments was $7.7 \%$ in favor of the I-75 treatment.

The calculated soil cover fraction from the NDVI values $\left(\mathrm{f}_{\mathrm{c}}{ }^{*}\right)$ was determined according to the Toureiro et al. 2017 procedure. The following equation was used:

$$
f_{c}^{*}=1.19\left(N D V I-N D V I_{s}\right)
$$

where, NDVIs gives the NDVI values for the bare soil whose value was taken 0.14 as the Toureiro et al. (2017) proposed. Usually, the $f_{c}{ }^{*}$ is related to the NDVI linearly (Gonzales-Dugo et al., 2006). The linear relation between these two parameters for the whole growing period is described by the following equations for the I-100, I-75, and I-50 treatments respectively:

$$
\begin{gathered}
(I-100) f_{c}^{*}=1.15 N D V I_{I-100}-0.115, \mathrm{R}^{2}=0.913 \\
(I-75) f_{c}^{*}=1.17 N D V I_{I-75}-0.148, \mathrm{R}^{2}=0.995 \\
(I-50) f_{c}^{*}=1.19 N D V I_{I-50}-0.163, \mathrm{R}^{2}=0.990
\end{gathered}
$$

The high values of the correlation coefficient $\left(\mathrm{R}^{2}\right)$ verified the linear relation between the $\mathrm{f}_{\mathrm{c}}{ }^{*}$ and the NDVI. However, the exponential relation between the $\mathrm{f}_{\mathrm{c}}{ }^{*}$ and the NDVI parameters was examined. The equations that describe that relation are given below:

$$
\begin{aligned}
(I-100) f_{c}^{*} & =0.116 e^{2.626 N D V I_{I-100}}, \mathrm{R}^{2}=0.856 \\
(I-75) f_{c}^{*} & =0.100 e^{2.832 N D V I_{I-75}}, \mathrm{R}^{2}=0.947 \\
(I-50) f_{c}^{*} & =0.090 e^{3.045 N D V I_{I-50}}, \mathrm{R}^{2}=0.956
\end{aligned}
$$

The last three equations describe the exponential relation between the $\mathrm{f}_{\mathrm{c}}{ }^{*}$ and the NDVI parameters with high accuracy, too, and are quite close to the results of other researchers (Toureiro et al., 2017).

The relation between the observed soil cover fraction $\left(f_{c}\right)$ and the estimated one from the NDVI values $f_{c} *$ is linear. The results are close to those referred to by Toureiro et al 2017. The following equation estimates the $f_{c}{ }^{*}$ from the $\mathrm{f}_{\mathrm{c}}$ values:

$$
f_{c}^{*}=0.805 f_{c}-0.134, \mathrm{R}^{2}=0.911
$$

This equation shows that, according to the Equation (21), the estimated $\mathrm{f}_{\mathrm{c}} *$ values are very close to the measured values of $f_{c}$.

\section{Conclusions}

The present study is part of a three-year long research project that took place at the experimental farm of the University of Thessaly in Central Greece. The objective was to study if it is feasible to use a low-cost multispectral camera and a drone to calculate vegetation indices in corn, in the Greek climatic conditions, and to use them to estimate the leaf area index and the soil cover fraction of the corn leaf area. It was the first time that such a study had been organized and implemented under the climatic conditions of Central Greece. A randomized complete block design with three irrigation treatments in three replications was used.

In general, vegetation indices based on multispectral photos taken from a drone can be used in LAI and soil cover fraction estimations. The results showed that the five different vegetation indices, the NDVI, the WDRVI, 
the RVI, the GNDVI, and the CIg, which were used as independent variables, can be used to estimate the LAI values of corn during the whole growing period with high accuracy. When the GNDVI index was used the LAI values were estimated with very high accuracy $\left(\mathrm{R}^{2}=0.99\right)$, regardless of whether the irrigation was full or deficit. The GNDVI gave the best results because it is more sensitive to the canopy development in comparison with the other four indices. The results are in close relation with other studies and given this fact, it could be said that the climatic conditions of Central Greece did not affect the use of vegetation indices in LAI estimations.

The soil cover fraction was also estimated with high accuracy. According to the results, Equation (21) can be used in the climatic conditions of Central Greece to estimate the $f_{c} *$. The estimated values were close enough to the measured values of fc. The irrigation dose affects the LAI and the soil cover fraction as well but the regression analysis gave estimation equations that better fit with the results of deficit irrigation in comparison with the full irrigation treatment. The fact that the $f_{c}^{*}$ and fc values are closely related is quite promising for future studies as regards the estimation of crop coefficient using multispectral photos in the climatic conditions of Central Greece.

Finally, once more this study confirms one more time that the multispectral photos taken from a drone that flies only a few meters above the ground can be used in irrigation management more effectively than the photos from satellites. The reasons are that such photos can be taken repeatedly at short intervals during the cultivation period in contrast with the satellite photos where the capture interval is high not to mention the fact that the clouds in the sky are not a restrictive factor for the quality of the photos. The results about the LAI and fc estimations are promising and they could be further used in future irrigation scheduling of plant water needs using drones.

\section{References}

Ambrosio, R., Pauletti, V., Barth, G., Pinheiro, P. P., Agostinho da Silva, D., \& Blum, H. (2017). Energy potential of residual maize biomass at different spacings and nitrogen doses. Ciência e Agrotecnologia, 41(6). https://doi.org/10.1590/1413-70542017416009017

Boedhram, N., Arkebauer, J. T., \& William, D. B. (2001). Season-Long Characterization of Vertical Distribution of Leaf Area in Corn. Agronomy Journal, 93, 1235-1242. https://doi.org/10.2134/agronj2001.1235

Chartzoulakis, K., \& Bertaki, M. (2015). Sustainable water management in agriculture under climate change. Agriculture and Agricultural Science Procedia, 4, 88-98. https://doi.org/10.1016/j.aaspro.2015.03.011

Din, M., Zheng, W., Rashid, M., Wang, S., \& Shi, Z. (2017). Evaluating Hyperspectral Vegetation Indices for Leaf Area Index Estimation of Oryza sativa L. at Diverse Phenological Stages. Frontiers in Plant Science, 8, 820. https://doi.org/10.3389/fpls.2017.00820

FAO (Food and Agriculture Organization). (1998). Crop evapotranspiration-Guidelines for computing crop water requirements. Rome: FAO.

Foster, J., Kakani, G., \& Mosali, J. (2017). Estimation of bioenergy crop yield and N status by hyperspectral canopy reflectance and partial least square regression. Precision Agriculture, 18(2), 192-209. https://doi.org/ $10.1007 / \mathrm{s} 11119-016-9455-8$

Gao, Y., Duan, A., Sun, J., Li, F., Liu, Z., Liu, H., \& Liu, Z. (2009). Crop coefficient and water-use efficiency of winter wheat/spring maize strip intercropping. Field Crops Research, 111, 65-73. https://doi.org/10.1016/ j.fcr.2008.10.007

Ghosh, K., Samui, P. R., \& Narayanan, S. P. (2003). Reflectance characteristics of maize and application of vegetation indices for estimation of leaf area index. Quarterly Journal of Meteorology, Hydrology and Geophysics, 54(4), 901-908. Retrieved from https://metnet.imd.gov.in/mausamdocs/154411_F.pdf

Gitelson, A. A. (2004). Wide dynamic range vegetation index for remote quantification of biophysical characteristics of vegetation. Journal of Plant Physiology, 161(2), 165-173. https://doi.org/10.1078/01761617-01176

Gitelson, A. A., Viña, A., Arkebauer, T. J., Rundquist, D. C., Keydan, G. P., \& Leavitt, B. (2003). Remote estimation of leaf area index and green leaf biomass in maize canopies. Geophysical Research Letters, 30(5), 52-1-52-4. https://doi.org/10.1029/2002GL016450

González-Dugo, M. P., Moran, M. S., Mateos, L., \& Bryant, R. (2006). Canopy temperature variability as an indicator of crop water stress severity. Irrigation Science, 24(4), 233. https://doi.org/10.1007/s00271005-0022-8 
Goupta, A., Sarangi, A., Singh, K. D., Parihar, S. S., \& Varghese, C. (2016). A software for crop coefficient estimation and irrigation scheduling. Green Farming Journal, 7(5), 1186-1191.

Hunt, E. R. J., Hively, W. D., Daugtry, C. S. T., \& McCarty, G. W. (2008). Proceedings of the Pecora 17 Conference, American Society for Photogrammetry and Remote Sensing. Denver, Colorado.

Lin, S., Li, J., Liu, Q., Li, L., Zhao, J., \& Yu, W. (2019). Evaluating the Effectiveness of Using Vegetation Indices Based on Red-Edge Reflectance from Sentinel-2 to Estimate Gross Primary Productivity. Remote Sensing Journal MDPI, 11, 1303. https://doi.org/10.3390/rs11111303

Maas, S. (2008). Irrigation Scheduling: Remote Sensing Technologies. In S. Trimple (Eds.), Encyclopedia of Water Science (pp. 606-610). CRC Press Taylor and Francis Group. https://doi.org/10.1201/NOE0849396274.ch144

Montgomery, C., \& Runger, C. (2003). Applied Statistics and Probability for Engineers (3rd ed.). New York: John Willey \& Sons.

Mulla, D. J. (2013). Twenty five years of remote sensing in precision agriculture: Key advances and remaining knowledge gaps. Biosystems Engineering, 114, 358-371. https://doi.org/10.1016/j.biosystemseng.2012.08.009

Nakanishi, T., Imai, Y., Morita, T., Akamatsu, Y., Odagawa, S., Takeda, T., \& Kashimura, O. (2012). Evaluation of wheat growth monitoring methods based on hyperspectral data of later grain filling and heading stages in Western Australia. International Archives of the Photogrammetry, Remote Sensing and Spatial Information Sciences, 39, 295-300. https://doi.org/10.5194/isprsarchives-XXXIX-B8-295-2012

Papanikoaloau, C., \& Sakellariou-Makrantonaki, M. (2019). Proceedings of the $7^{\text {th }}$ International Conference on Environmental Management Engineering, Planning and Economy (SEMEPE and SECOTOX). Mykonos Island, Grafima Publications.

Papanikoaloau, C., \& Sakellariou-Makrantonaki, M. (2020). Effect of Irrigation Dose Based on Vegetation Indices Calculation Using Multispectral Sensor. Journal of Agricultural Science, 12(11), 107-122 https://doi.org/ 10.5539/jas.v12n11p107

Papanikolaou, C., \& Sakellariou-Makrantonaki, M. (2012). The effect of an intelligent surface drip irrigation method on sorghum biomass, energy and water saving. Irrigation Science, 31(4), 807-814. https://doi.org/ $10.1007 / \mathrm{s} 00271-012-0344-2$

Papanikolaou, C., Giouvanis, V., Karatasiou, E., Dimakas, D., \& Sakellariou-Makrantonaki, M. (2018). Sunflower Irrigation with Two Different Types of Soil Moisture Sensors. International Journal of Biological, Biomolecular, Agricultural, Food and Biotechnological Engineering, 12(8), 255-259. Retrieved from https://waset.org/Publication/10009426

Potgieter, B., George-Jaeggli, B., Chapman, C., Laws, K., Suarez Cadavid, A., Wixted, J., ... Hammer, L. (2017). Multispectral imaging from an unmanned aerial vehicle enables the assessment of seasonal leaf area dynamics of sorghum breeding lines. Frontiers in Plant Science, 8, 1532. https://doi.org/10.3389/fpls.2017.01532

Ryu, C., Suguri, M., \& Umeda, M. (2009). Model for predicting the nitrogen content of rice at panicle initiation stage using data from airborne hyperspectral remote sensing. Biosystems Engineering, 104(4), 465-475. https://doi.org/10.1016/j.biosystemseng.2009.09.002

Sakellariou-Makrantonaki, M., \& Papanikolaou, C. (2008a). Proceedings of Protection and Restoration of the Environment IX. Kefalonia Island, Greece.

Sakellariou-Makrantonaki, M., \& Papanikolaou, C. (2008b). Proceedings of $2^{\text {nd }}$ WSEAS/IASME International Conference on Renewable Energy Sources. Corfu Island, Greece.

Sakellariou-Makrantonaki, M., Papanikolaou, C., \& Mygdakos, E. (2009). Fiber sorghum biomass yield, water use efficiency and economicresults under different levels of water using subsurface and surface irrigation systems. Fresenius Environmental Bulletin, 18(9), 1624-1632.

Savva, P.A., Frenken, K., Mudima, K., Chitima, M., \& Tirivamwe, L. (2002). Crop Water Requirements and Irrigation Scheduling. Irrigation Manual (Module 4). Retrieved from http://www.fao.org/3/a-ai593e.pdf

Shahrokhnia, H. M., \& Sepaskhah, R. A. (2013). Single and dual crop coefficients and crop evapotranspiration for wheat and maize in a semi-arid region. Theoretical and Applied Climatology Journal, 114, 495-510. https://doi.org/10.1007/s00704-013-0848-6 
Sylvester, G. (2018). E-Agriculture in action: Drones for agriculture. Food and Agriculture Organization of the United Nations (FAO) and International Telecommunication Union, Bangkok. Retrieved from http://www.fao. org/3/i8494en/i8494en.pdf

Toureiro, C., Serralheiro, R., Shahidian, S., \& Sousa, A. (2017). Irrigation management with remote sensing: Evaluating irrigation requirement for maize under Mediterranean climate condition. Agricultural Water Management, 184, 211-220. https://doi.org/10.1016/j.agwat.2016.02.010

Towers, P., Strever, A., \& Poblete-Echeverría, C. (2019). Comparison of Vegetation Indices for Leaf Area Index Estimation in Vertical Shoot Positioned Vine Canopies with and without Grenbiule Hail-Protection Netting. Remote Sensing, 11, 1073. https://doi.org/10.3390/rs11091073

USDA (United States Department of Agriculture). (2004). Farm and Ranch Irrigation Survey (2003). United States Department of Agriculture/National Agricultural Statistic Service Washington, DC. Retrieved from http://www.nass.usda.gov

Watson, D. J. (1956). Leaf growth in relation to crop yield. In F. L. Milthorpe (Eds.), The Growth of Leaves (pp. 178-191). Butterworth, UK.

Williams, R. F. (1946). The physiology of plant growth with special references to the concept of net assimilation rate. Annals of Botany, 10, 41-72. https://doi.org/10.1093/oxfordjournals.aob.a083119

Xue, J., \& Su, B. (2017). Significant remote sensing vegetation indices: A review of developments and applications. Hindawi Journal of Sensors, 1-18. https://doi.org/10.1155/2017/1353691

\section{Copyrights}

Copyright for this article is retained by the author(s), with first publication rights granted to the journal.

This is an open-access article distributed under the terms and conditions of the Creative Commons Attribution license (http://creativecommons.org/licenses/by/4.0/). 